\title{
CONSULTA TRAMPOSA: \\ interpretações sobre o direito entrecortadas pela política ${ }^{1}$
}

CONSULTA TRAMPOSA:

interpretations about the law crossed by politics

CONSULTA TRAMPOSA:

interpretaciones acerca del derecho atravesadas por la política

Renata Albuquerque

Doutora em Antropologia Social

Faculdade Cásper Líbero

re.a.moraes@gmail.com

Brasil

ORCID https://orcid.org/0000-0002-8524-1764

\section{Resumo}

O Território Indígena e Parque Nacional Isiboro Sécure (TIPNIS) é um dos maiores territórios indígenas da Bolívia, localizado entre as terras baixas e as terras altas do país, nos pies de monte bolivianos. Ali vivem três povos indígenas diferentes, que se dividem entre as sessenta e quatro comunidades espalhadas pela região. Desde 2011 o TIPNIS passa a ocupar um papel de destaque no campo político nacional, mobilizando atores contra e a favor do projeto governamental de construção de uma estrada através do território. Este trabalho analisa interpretações de lideranças indígenas bolivianas do TIPNIS sobre a consulta realizada pelo governo do Estado Plurinacional

\footnotetext{
${ }^{1}$ Paper originalmente apresentado no Grupo de Trabalho 4, intitulado «Consulta prévia, livre e informada e protocolos próprios de consulta: experiências de autonomia política e diálogo intercultural no Brasil», do VI ENADIR (Encontro Nacional de Antropologia do Direito), ocorrido entre 26 e 29 de agosto de 2019 na FFLCH-USP (Faculdade de Filosofia, Letras e Ciências Humanas da Universidade de São Paulo).
} 
da Bolívia em 2012 sobre o referido projeto. O objetivo central do artigo é discutir como interpretações sobre direitos indígenas, o direito à consulta prévia em particular, foram entrecortadas pela conjuntura política nacional e modificadas pelas disputas por hegemonia, revelando um campo político indígena complexo e plural. A polarização política entre governistas e opositores se transportou para o território ao longo da consulta, germinando em um ambiente de incertezas e necessidades para desabrochar enquanto divisão, desconfiança e aversão à política. A consulta, no TIPNIS, não é uma lembrada como uma conquista, mas como um momento em que "los políticos" impuseram suas vontades às comunidades.

Palavras-chave: Política Indígena. Consulta Prévia. Bolívia. Amazônia. Direitos Indígenas

\begin{abstract}
Isiboro Secure National Park and Indigenous Territory (TIPNIS) is one of the biggest indigenous territories in Bolivia. It is located between the lowlands and the highlands of the country, in an area called pies de monte. Three different indigenous people live there, divided through sixty-four communities scattered throughout the region. Since 2011, different TIPNIS' indigenous leaders have been playing a prominent role in the national political field, mobilizing actors against and in favor of a governmental project of building a road through the territory. This paper analyzes different interpretations about a consultation carried out by the Plurinational State of Bolivia in 2012 on the referred project. The main objective of the article is to discuss how interpretations of indigenous rights, the right to prior consultation in particular, were crossed by the national political situation and modified by disputes over hegemony, revealing a complex and plural indigenous political field. The political polarization between government officials and opponents took place in the territory during the consultation, germinating in an environment of uncertainty and outcropping as division, distrust and aversion to politics. At least in that area, the consultation is not remembered as indigenous right's victory, but as a moment in which "los políticos" imposed their will on communities.
\end{abstract}

Keywords: Indigenous Politics. Previous Consultation. Bolivia. Amazon. Indigenous Rights

\title{
Resumen
}

El Territorio Indígena y Parque Nacional Isiboro Sécure (TIPNIS) es uno de los territorios indígenas más grandes de Bolivia, y está ubicado entre las tierras bajas y las tierras altas del país. En esa zona viven tres pueblos indígenas diferentes, que se distribuyen entre las sesenta y cuatro comunidades esparcidas por la región. Desde el 2011 el TIPNIS juega un papel destacado en el campo político nacional, movilizando actores a favor y en contra del proyecto gubernamental de construcción de una carretera por el territorio. El presente trabajo analiza las interpretaciones de los líderes indígenas bolivianos del TIPNIS sobre la consulta realizada por 
el gobierno del Estado Plurinacional de Bolivia en 2012 sobre el referido proyecto. El objetivo principal del artículo es discutir cómo las interpretaciones de los derechos indígenas, en particular el derecho a la consulta previa, fueron atravesadas por la situación política nacional y modificadas por las disputas por hegemonía, revelando un campo político indígena complejo y plural. La polarización política entre funcionarios del gobierno y opositores se trasladó al territorio durante la consulta, germinando en un ambiente de incertidumbre y necesidades diversas y floreciendo como división, desconfianza y aversión a la política. La consulta, en el TIPNIS, no se la recuerda como un logro, sino como un momento en el que "los políticos" impusieron su voluntad a las comunidades.

Palabras clave: Política Indígena. Consulta Previa. Bolivia. Amazonía. Derechos Indígenas 
Território Indígena e Parque Nacional Isiboro Sécure (TIPNIS) é um dos maiores territórios indígenas da Bolívia e, por também ser um Parque Nacional, é uma das vinte e duas Áreas Protegidas do país. De acordo com o titulo ejecutorial entregue pelo governo de Evo Morales à Subcentral do TIPNIS em 2009, tem uma área de 1.951.656 hectares. No território existem sessenta e quatro comunidades indígenas que se distribuem entre a zona do Sécure alto, do Sécure baixo, a zona do Isiboro baixo, a zona central e a zona sul (Isiboro alto). São comunidades mojeño-trinitárias, yuracarés e chimánes que variam no tamanho de suas populações e na quantidade (e qualidade) de infraestrutura de que dispõem (como escolas, postos de saúde, eletricidade, bombas de água, comércio, casas de alvenaria, pistas de avião, etc). A proposta de construção de uma estrada através do TIPNIS surge em 2003 com o Decreto 26996, promulgado pelo então presidente da Bolívia Gonzalo Sánchez de Lozada. Ela foi planejada para ligar as cidades de Villa Tunari e San Ignacio de Moxos e se construída teria ao redor de $300 \mathrm{~km}$ de extensão. A estrada seria dividia em três trechos; o segundo, previsto para ter $177 \mathrm{~km}$, deveria atravessar o TIPNIS. Neste trecho, prevê-se $60 \mathrm{~km}$ atravessando o coração do parque, uma área isolada onde ainda não há contato com os colonos que já habitam outras regiões da terra indígena. É ao redor da construção deste trecho que estão as grandes polêmicas sobre a construção da estrada.

Como bem diagnosticou Schavelzon (2016, p. 8), desde a eleição de Evo Morales para a presidência da Bolívia se consolidou em todo o mundo a imagem de que um tempo indígena se instaurava naquele país, ainda que, paralelamente, a lógica desenvolvimentista clássica se alastrasse e fosse reivindicada como política de Estado. É possível reconhecer variados esforços do governo de Evo Morales de reafirmar e propagar a retórica do tempo indígena. São exemplos a cerimônia de posse de 2010 e 2015, quando Morales é empossado presidente em Tiwanaku, sítio arqueológico pré-incaico que já foi a capital do antigo império; a aparição do Vivir Bien como conceito fundamental do novo Estado Plurinacional; a aprovação da Ley Marco de la Madre Tierra em 2012; e a apropriação, por parte do oficialismo, dos discursos sobre o Pachakuti - ideia de transformação da ordem geral do universo contida na percepção andina de um tempo não linear. Pachakuti significa a mudança profunda da sociedade ou o retorno do tempo de equilíbrio; uma mudança de Era, que Morales quis mobilizar para qualificar o início do seu governo com elaborações oriundas da cosmologia andina ancestral. 
Com a intensificação dos conflitos no TIPNIS essa retórica parece mais frágil, mais contraditória. Fica mais difícil convencer que o tempo indígena se instaurou na Bolívia. Em minha dissertação de mestrado, por exemplo, mostrei como o discurso sobre o Vivir Bien convive com o desenvolvimentismo clássico na Bolívia (MORAES, 2014).

Este trabalho também revisa a ilustração sobre o "tempo indígena" da Bolívia, lançando luz sobre a experiência de uma consulta realizada dentro do TIPNIS. Analiso interpretações de lideranças indígenas bolivianas do TIPNIS sobre a consulta realizada pelo governo do Estado Plurinacional para discutir como interpretações sobre direitos indígenas foram entrecortadas pela conjuntura política nacional e modificadas pelas disputas por hegemonia que revelaram um campo político indígena complexo e plural. Neste artigo discuto como a análise etnográfica da política indígena boliviana permite entrever interpretações sobre o direito dos povos indígenas à consulta prévia. Organizo o comentário a partir de dados etnográficos reunidos durante a pesquisa de campo, realizada entre 2013 e 2016, e a partir da análise de documentos diversos sobre a consulta prévia, produzidos pelas organizações indígenas, por ONGs bolivianas, pela Igreja Católica e pelo
Estado Plurinacional. A pesquisa foi pautada pela etnografia, informada por elaborações sobre etnografia colaborativa e fundamentalmente realizada enquanto uma observação participante. Algumas entrevistas foram realizadas e também oferecem dados que fortalecem a análise. As etapas da pesquisa que interessam a este artigo foram realizadas em diferentes comunidades do TIPNIS, especialmente em Puerto San Lorenzo, comunidade mojeñotrinitária profundamente impactada pela experiência da consulta e pela chegada das brigadas governamentais que a operaram.

\section{As marchas indígenas das terras baixas}

Os povos indígenas das terras baixas bolivianas, toda a parte não-andina do país (também conhecida como Oriente), desde a década de 1990 têm investido nas marchas como seu principal instrumento político. Naquele começo de década organizaram sua primeira grande marcha - Por el Territorio y la Dignidad - que sem dúvida foi o principal episódio político daquela região. A I Marcha comportou uma pluralidade de visões e sentidos sobre a política e sintetizou essa diversidade tornando-se um episódio singular (cf. CONTRERAS, 1991; LEHM, 1999; ALBÓ, 2012; ALBUQUERQUE, 2019). Além de configurar um protótipo 
organizativo para aquela região, a marcha tem conquistas mais objetivas, como a criação dos territórios indígenas bolivianos. O TIPNIS é um dos primeiros territórios indígenas a ser criado, é uma conquista da I Marcha.

Em 2011, mais de vinte anos depois, as comunidades do TIPNIS são convocadas a se engajar em uma nova luta em defesa de seu território, outra vez com uma agenda capaz de fundir os horizontes políticos das organizações e das comunidades indígenas - horizontes que nem sempre coincidem apesar de estarem conectados. Outras marchas haviam sido realizadas nesse meio tempo, principalmente durante a antessala da criação do Estado Plurinacional. Houve marchas reivindicando a revisão da reforma agrária de 1952 (em 1996, com a finalidade de reconhecer novos territórios indígenas); a defesa dos recursos naturais (nos anos 2000); uma marcha por uma constituinte no país (em 2002, no contexto efervescente da Guerra do Gás); por uma nova revisão da lei INRA (em 2006, no primeiro ano da gestão Morales); e duas marchas, já no contexto do Estado Plurinacional, em defesa das Autonomias Indígenas ${ }^{2}$.

Em 2011 descobre-se que o governo do país havia assinado um convênio com a empreiteira brasileira OAS, para que ela elaborasse e executasse um projeto para a

\footnotetext{
2 Para mais informações sobre as Marchas indígenas na Bolívia, há material organizado sobre o assunto na
}

construção de uma estrada entre os municípios de Villa Tunari e San Ignacio de Moxos. Ninguém havia sido consultado ou informado sobre o projeto, que foi sendo desenvolvido na surdina entre 2008 e 2011. Desde aquele momento a luta contra a estrada começa a tomar formas de plataforma política de oposição, ao mesmo tempo em que é uma estratégia de luta pela sobrevivência das comunidades. Os dirigentes organizaram uma nova marcha que saiu de Trinidad como uma marcha contra a estrada e em defesa do TIPNIS, e chegou em La Paz como a principal expressão de uma nova oposição política ao governo de Evo Morales.

Apesar de comunarios e dirigentes marcharem juntos e com um objetivo comum (a luta contra a estrada), não necessariamente compartilhavam as disputas ideológicas e utópicas travadas entre dirigentes oposicionistas e o governo. A agenda política oposicionista difundida entre alguns segmentos do movimento indígena das terras baixas não se replicava automaticamente nas comunidades, que em um primeiro momento marchavam pelo território, mas não necessariamente contra o governo, como pude perceber através de relatos e entrevistas. No meio do caminho entre Trinidad e La Paz, em Chaparina, tudo

minha dissertação de mestrado (MORAES, 2014) e na tese de doutorado (ALBUQUERQUE, 2019). 
começa a se transformar. Uma experiência de repressão e violência fortalece a postura oposicionista entre as colunas que marchavam contra a estrada, e esse evento desencadeia uma onda nacional e internacional de questionamento e enfrentamento ao governo de Morales. Em vinte e cinco de setembro de 2011, no povoado de Chaparina, a VIII Marcha indígena foi surpreendida, reprimida e atacada pela polícia, supostamente a mando de membros do governo boliviano. Até hoje ninguém foi responsabilizado pela ação.

As imagens dos eventos em Chaparina rapidamente circularam pelo país e repercutiram na imprensa internacional. No dia seguinte à repressão, o governo de Evo Morales começa a desmontar, com a renúncia da então ministra de defesa Cecília Chacón. Nos dias que se seguiram outros membros do governo seguiram renunciando: um vice-ministro, uma funcionária do Ministério de Desenvolvimento Rural e a diretora de Migrações (CONTRERAS, 2012, p. 112). Chaparina marcava o início de um segundo tempo do governo Morales, no qual importantes segmentos populares rompiam com o governo e passavam a questionar de frente o projeto de país do Movimiento al Socialismo - Instrumento Político para la Soberania de los Pueblos (MAS-IPSP), o partido de Evo Morales. Também marcava um segundo tempo para as políticas indígenas que começariam a tecer outros horizontes para si. O Pacto de Unidade começava a se dissolver, já que a Confederación de Pueblos Indígenas de Bolivia e o Consejo Nacional de Ayllus y Markas del Qullasuyu, as organizações que representam as nações e povos indígenas originários da Bolívia a nível nacional, se deslocavam para o campo da oposição. A repressão em Chaparina aproximou a luta contra a estrada da luta contra o governo, definindo um novo campo de atuação entre os indígenas das terras baixas e justificando a atuação de alguns dirigentes no campo político departamental e nacional. Indígenas se mobilizam contra indígenas no campo político que se revela ao seu redor, em uma interessante manobra que vai criando novas estratégias de ação.

Quando a VIII Marcha chega à capital paceña em dezenove de outubro, quase um mês depois de Chaparina, meio milhão de pessoas havia tomado as ruas para demonstrar seu apoio ao TIPNIS. Os últimos onze quilômetros de marcha até a Plaza Murillo, onde está localizada a sede do governo, foram percorridos por mais de três mil pessoas. Como em 1990, os relatos sugerem uma recepção emocionante na cidade: "a los marchistas les llovían flores por los costados, papeles picados desde los edifícios, algunos paceños sobrepasaban el cerco de citadinos para alcanzar uma 
bolsita de agua, un jugo, unas galletas a los recién llegados" (CIDOB et al., 2012, p. 217). A cidade ainda carrega as marcas desse episódio. Nas vezes em que estive em La Paz, encontrei pichações declarando apoio aos marchistas em diversas partes. Núcleos e comitês de apoio ao TIPNIS apareceram em La Paz, em Cochabamba e em Santa Cruz, as maiores cidades da Bolívia. A repressão à marcha despertou uma gigantesca comoção nacional e uma evidente solidariedade aos marchistas, que mesmo depois do ocorrido se recompuseram, seguiram o seu caminho e chegaram a La Paz.

A VIII Marcha, assim como outras grandes marchas, foi um "fato criador de fatos" (CHAVES, 2000, p. 11), um episódio que disparou fenômenos sociais e políticos translocais, como a paralisação das obras e a suspensão do contrato com a OAS, a partidarização da oposição indígena ao governo, a organização de uma base política aliada ao MAS dentro do território, a instauração de um processo na Comissão Interamericana de Direitos Humanos, etc. O episódio já se localiza entre os grandes eventos políticos da história da Bolívia. Para muitos analistas, isso se justifica porque ela questionou a capacidade transformadora do Estado Plurinacional, desafiando o modelo de desenvolvimento vigente no país depois do início do processo de

transformação

boliviano

(CONTRERAS, 2012; GÚZMAN, 2012; PAZ, 2012). Eu mesma realizei minha primeira pesquisa sobre o TIPNIS atentando às tensões que o conflito produzia nos discursos sobre o novo modelo de desenvolvimento nacional boliviano baseado no Vivir Bien, mas hoje percebo que o principal traço do conflito é outro. Para Sarela Paz, além de desafiar o modelo econômico vigente e de também evidenciar os desafios institucionais do Estado Plurinacional no contexto regional, a VIII Marcha é um evento político importante por representar uma manifestação estratégica de determinados segmentos sociais indígenas sobre as formas políticas e as formas econômicas em curso (PAZ, 2012, p. 14). Esse me parece ser o ponto mais importante da análise proposta pela antropóloga boliviana, pois antecipa a instauração de um novo momento das relações entre povos indígenas e política na Bolívia.

Com a grande repercussão da chegada da VIII Marcha em outubro de 2011, depois da brutal repressão em Chaparina e dos percalços do trajeto, o governo não teve outra alternativa senão negociar com a direção da marcha. $\mathrm{O}$ resultado foi a promulgação da Ley Corta 180, a lei de intangibilidade do TIPNIS. A lei 180 proibia a construção daquela ou de qualquer outra estrada através do território 
(Art. 3), e ratificava o TIPNIS como território dos povos mojeño-trinitários, yuracarés e chimánes (Art. 1, § 2). A parte mais polêmica da lei é a que estabelecia o TIPNIS como território intangível (Art. 1, § 3). Como a lei não fazia mais do que anunciar essa nova qualidade da região, ela deixou espaço para diferentes interpretações sobre seu significado. Para os segmentos afins ao governo, que imediatamente reagiram à lei 180 por defenderem a construção da estrada, o caráter intangível do TIPNIS significaria que nada mais poderia ser feito naquela região: nem uma árvore poderia ser derrubada, nem um animal morto, nem uma escola construída, nem uma roça queimada, nem um novo caminho aberto. Eles propagavam desde aquele momento que a lei deveria ser barrada, pois ela inviabilizaria a vida no território. Uma interpretação profundamente política da lei 180, que pretendia beneficiar o governo e garantir seu projeto viário. O enfrentamento à intangibilidade do TIPNIS, desde aquele momento e até 2017, impulsionou o enfrentamento à grande vitória da marcha: aquela lei que proibia a construção da estrada Villa Tuanri-San Ignacio de Mojos.

Com o argumento de defesa dos interesses das comunidades do TIPNIS, contra a lei 180, declaradamente contra a intangibilidade do TIPNIS e consequentemente contra a proibição do projeto viário previsto para atravessar o território, dirigentes da zona sul do parque (do Consejo Indígena del Sur, o CONISUR) organizam, ainda em 2011, uma contramarcha do TIPNIS até La Paz. Essa nova marcha não saiu da Amazônia, mas dos pés dos Andes bolivianos, na região sul do TIPNIS que é mais próxima a Cochabamba e onde se localizam comunidade indígenas e comunidades camponesas onde se planta folha de coca. Esses setores do CONISUR estavam articulados com segmentos do movimento indígena que já atuavam lado a lado com quadros políticos do MAS. O conflito foi reconstruído a partir da disputa pelo sentido e importância da intangibilidade territorial e o que era um conflito dos indígenas com o governo se transformou em um conflito entre indígenas do TIPNIS. O tema da intangibilidade criou uma batalha interpretativa entre as lideranças indígenas oposicionistas e governistas dentro do campo político boliviano, transformando o conflito em algo que deveria ser resolvido internamente entre os indígenas. Essa transformação foi decididamente estimulada pelo governo que, diante da chegada da contramarcha a $\mathrm{La} \mathrm{Paz}$, anunciou que a questão da estrada e da intangibilidade do TIPNIS já não seria decidida pelo governo e sim por uma consulta realizada entre as comunidades, dentro do território. Ainda sob a vigência da lei de intangibilidade, em 
fevereiro de 2012 é promulgada a lei 222, conhecida como a lei de consulta.

\section{Consulta prévia: direito ou trampa?}

Era mais um final de tarde, em setembro de 2016, em Puerto San Lorenzo, comunidade localizada no rio Sécure. Eu conversava com a então capitán-grande da comunidade, hoje presidenta da organização de mulheres do TIPNIS, doña Marquesa Teco. Finalmente havíamos decidido gravar uma entrevista, depois de algumas semanas em que eu vivia em sua casa, com sua família. A conversa passou pela história da sua vida e pela história da comunidade e invariavelmente chegou ao tema da consulta realizada no território em 2012. Puerto San Lorenzo foi uma das comunidades do TIPNIS mais afetadas pela consulta e desde então está profundamente dividida. Na entrevista, doña Marquesa narrava esses acontecimentos. Comentava que "desde que hubo la consulta, ahí empezó las divisiones. Aquí éramos bien unidos, no había divisiones. Cuando había una cosa de por allá de la ciudad se tocaba el bombo y nos íbamos toditos, ¿no?’. Os bombos são tocados por um membro do cabildo da comunidade e significam que o corregedor ou outra autoridade estão convocando uma reunião comunal. Doña
Marquesa relembra que os assuntos que vinham "de allá de la ciudad" eram discutidos na reunião, e que "todos opinábamos, a veces decíamos 'no, no queremos '”. Depois de 2012, a realidade da comunidade mudou. Poucas pessoas respondiam aos chamados para as reuniões, aos bombos, e os espaços de discussão, assim, foram se tornando mais restritos, com pouca participação: “cuando llegó la consulta ya empezó la desunión. A veces tres familias no más se reunían, ya no había el bombo que suene. Desde ahí empezó la desunión" (22/09/16).

A antropóloga boliviana Sarela Paz afirma que "la Consulta Previa a los pueblos indígenas se basa en el derecho colectivo de los pueblos a la libre determinación" e que "la consecuencia primaria de la libre determinación es su carácter vinculante como decisión hacia el Estado, mucho más si el contenido político del Estado es Plurinacional" (2012, p. 30, grifos meus). O direito à consulta prévia, libre, informada e de boa fé, portanto, deveria ser um dos pilares do projeto estatal plurinacional. Ele está previsto na Constituição Política do Estado (Art. 30, 304, 352, 403, 401) e reflete os avanços conquistados pelos povos indígenas no cenário internacional diante das agências multilaterais. Os povos indígenas têm o direito de ser consultados em diversas situações diferentes, não apenas (mas 
também) quando seu território será afetado diretamente por projetos de desenvolvimento. Esse direito foi primeiro estabelecido em 1989 através da Convenção 169 da Organização Internacional do Trabalho nos artigos 6, 15, 17, 22, 27 e 28 . Nos artigos 15, 17, 19, 30, 32, 36 e 38 da Declaração das Nações Unidas sobre os Direitos dos Povos Indígenas, de 2008, há referência ao direito dos povos indígenas de serem consultados sobre temas que lhes interessem. O documento mais recente sobre o tema é a Declaração Americana sobre os Direitos dos Povos Indígenas, aprovada em 2016, que nos artigos 18, 20, 23, 28 e 29 também versa sobre o direito à consulta.

Em todos os exemplos mencionados acima o direito à consulta prévia foi considerado uma enorme conquista dos povos indígenas das Américas e do mundo. $\mathrm{O}$ direito à consulta parte de pelo menos três fundamentos: primeiro, do reconhecimento da diversidade étnica e cultural de um Estado; segundo, do direito à autodeterminação dos povos que deveriam ter espaço institucional para organizar suas prioridades, especialmente no que se refere ao seu território; e terceiro, parte do direito que os povos indígenas têm, como donos de seus territórios, de participar dos planos de formulação, aplicação e avaliação dos planos e projetos de desenvolvimento nacional que lhes afetem diretamente
(CHARRIS, 2014, p. 125). O direito à consulta, portanto, expressa o reconhecimento, por parte do Estado, de que os povos indígenas devem sempre ser parte ativa e protagonista dos processos de decisão sobre sua vida e seu futuro. Para Santamaría (2016, p. 232), no cenário internacional as consultas se fortalecem cada vez mais como uma ferramenta de defesa dos povos indígenas, sobretudo no que se refere à exigência de consentimento livre, prévio e informado como condição sine qua non para a realização de determinados projetos.

No caso da Bolívia, e especificamente da consulta realizada aos três povos que vivem no Território Indígena e Parque Nacional Isiboro Sécure, é preciso ter cautela. Doña Marquesa não era uma voz dissonante quando afirmava que a consulta ao TIPNIS tinha sido a origem dos problemas da região. É preciso levar essa declaração a sério para entender a dinâmica das políticas indígenas no Estado Plurinacional. Na Bolívia, e em todos os lugares, não é suficiente realizar uma análise abstrata da situação dos direitos humanos, civis e políticos dos povos indígenas. A análise antropológica de processos como a consulta ao TIPNIS permite que a experiência real das comunidades sobressaia e que a localização dos povos indígenas no campo político nacional seja reconstruída a partir daí. Isso significa que mesmo em um Estado 
Plurinacional - ou ainda, especialmente em um Estado Plurinacional - é preciso analisar o impacto das políticas governamentais realizadas em um território indígena a partir de como ela é percebida por quem vive ali; interpretar o significado da política e não apenas reconhecê-la. À primeira vista pode parecer que a decisão do governo boliviano corresponde aos seus esforços de transformação e plurinacionalização, pois institui a realização de uma consulta prévia como mecanismo de solução de um conflito sobre um projeto de desenvolvimento. Acontece que essa narrativa não considera aspectos normativos, contextuais e procedimentais da consulta que permitem a interpretação de que ela se converteu em um problema político para as comunidades do território. Uma trampa, uma armadilha política, como afirmam insistentemente no território.

\section{A consulta tramposa}

$\wedge$

A consulta tal como prevista pela lei 222 (Art. 9) não se fazia fácil de entender e escamoteava a discussão sobre a estrada. Apesar de toda aquela situação polêmica e conflituosa ter sido sobre a construção da estrada Villa Tunari - San Ignacio de Mojos através do TIPNIS, a consulta não perguntava diretamente se as comunidades da região estavam a favor ou contra o projeto. A primeira pergunta da consulta era sobre a permanência do caráter intangível do território tal como previa a lei 180. A intangibilidade havia sido inventada pelos segmentos pró-governo como a proibição de tocar qualquer recurso natural do território, incluindo a terra, as plantas e os animais. Por isso, segundo esses segmentos, ela deveria ser esquecida e derrubada. Os segmentos que marcharam contra o governo interpretavam a intangibilidade como uma proteção, e afirmavam (e ainda afirmam) que ela era a principal defesa das comunidades contra projetos indesejados e mesmo contra o avanço da agricultura cocalera ao sul do parque. Para eles a intangibilidade não se referia às atividades produtivas cotidianas, que poderiam continuar sendo desenvolvidas nas comunidades normalmente. Diante de uma ampla rejeição ao projeto viário no território, o governo preferiu debater a questão da intangibilidade com as comunidades.

De acordo com os informes oficiais das brigadas da consulta (BOLIVIA, 2012), estava previsto que o tema da estrada só seria discutido caso as comunidades decidissem contra a intangibilidade. Foi armado um cenário onde se organizaram dois blocos distintos de interesse, que em seguida continuaram polarizados quando o assunto deixou de ser a intangibilidade e passou a ser a estrada. Criou-se a impressão de que havia continuidade entre ser contra a intangibilidade e ser a favor da estrada. As opiniões contrárias 
à estrada foram inibidas e o TIPNIS se dividiu entre aqueles que tinham aceitado a consulta e rejeitado a intangibilidade e aqueles que rejeitavam a consulta e defendiam a intangibilidade: o Estado conseguiu conformar o conflito de acordo com o seu interesse. A rejeição à realização da consulta em algumas comunidades tinha que ver com o contexto de sua realização. Muitas comunidades entendiam que a presença do governo no território não tinha a finalidade de consultar as comunidades sobre a estrada, uma vez que partes dos seus trechos um e três já estavam em construção. O TIPNIS foi aprisionado entre esses dois trechos, e há quem argumente que a obra deve ser concluída para que os recursos já investidos não sejam desperdiçados. Tanto o trecho um, que sai de Villa Tunari, quanto o trecho três, que chega em San Ignacio de Mojos, desembocam no TIPNIS, como pude conferir durante uma inspeção do trecho três que realizamos em 2016.

Quando a lei de consulta foi aprovada em fevereiro de 2012, ela foi rejeitada por quem tinha participado da marcha de 2011 enquanto uma saída para a situação de conflito que se apresentava no TIPNIS. O contrato assinado com a OAS em 2008 e o início das obras dos trechos um e três inviabilizavam que a consulta de fato fosse prévia, e a centralidade do debate sobre intangibilidade prevista pela lei abria espaço para dúvidas sobre a boa fé com que a consulta seria operada. As previsões constitucionais sobre a consulta prévia, livre, informada e de boa fé já não poderiam ser cumpridas. As organizações indígenas em resistência decidem seguir com sua mobilização, convocam as comunidades mais uma vez e organizam uma nova marcha à La Paz. Em vinte e sete de abril de 2012 a IX Marcha Indígena sai de Trinidad, tendo como lema central a defesa do TIPNIS. Cerca de quinhentas pessoas saíram com a marcha, e depois de sessenta e dois dias de caminhada chegaram na sede do governo com mais de mil pessoas. Além do que já foi apresentado, aspectos procedimentais da consulta também colaboraram para que ela tenha se tornado um problema político no TIPNIS. Na verdade, talvez esses sejam os elementos mais importantes da questão e os que alimentam a caracterização da consulta como trampa. Existem muitas denúncias sobre a metodologia de trabalho das brigadas governamentais que entraram no território para realizar a consulta. De saída, elas estimularam que comunarios se colocassem uns contra os outros, buscando aliados para si mesmos nas comunidades que haviam decidido coletivamente que iriam rejeitar a consulta. Em várias das comunidades que visitei relatam que as reuniões da consulta, pelo motivo acima citado, não foram realizadas no cabildo da comunidade, que em muitas dessas reuniões apenas poucas famílias compareceram e que em várias 
delas o próprio corregedor da comunidade não era convocado.

As brigadas da consulta além de forçarem sua presença em muitas comunidades e de não respeitarem o espaço do cabildo e as suas autoridades, tinham a liberdade de oferecer projetos produtivos de pequeno, médio ou grande porte em troca da consulta. As comunidades (ou as famílias) que aceitaram a consulta ganharam facões, motores de barco, painéis solares para energia, bombas de água e até projetos como escolas, quadras poliesportivas e postos de saúde. Consolidava-se a máxima de que rejeitar a consulta era rejeitar a presença do Estado e através da aceitação ou da rejeição de "presentes" e projetos as comunidades foram catalogando umas às outras como aliadas ou contrárias ao governo. A divisão se aprofundava cada vez mais. No rio Sécure, que já contava com duas diretorias que se reivindicavam legítimas representantes da sua Subcentral, as comunidades que respaldavam a gestão pró-governo recebiam projetos negociados pelo seu presidente, Carlos Fabricano, diretamente com o ministro da presidência, Juan Ramón Quintana - braço direito de Evo Morales desde sua primeira gestão e porta-voz do governo no Beni.

\footnotetext{
${ }^{3}$ As comunidades do TIPNIS pertencem aos municípios de San Ignacio de Mojos (província Mojos, Beni),
}

Diziam na comunidade de Coquinal que "se uno quiere trabajar al lado del gobierno va a tener de todo", e no TIPNIS não há quem duvide disso - seja apoiador ou opositor. É a partir desse entendimento que a consulta conseguiu chegar em algumas comunidades, que temiam estar cortando vínculos com o governo e em última instância abdicando de seus direitos como cidadãos caso não recebessem a brigada da consulta. As comunidades que receberam a consulta viram nessa visita uma oportunidade de comunicar suas necessidades e o governo foi ganhando acesso ao território enquanto prometia escutar e atender essas demandas. $\mathrm{O}$ programa governamental intitulado Evo Cumple serviu como um guarda-chuva orçamentário para essas práticas (cf. ALBUQUERQUE, 2019, segundo capítulo). O programa funciona sem uma agenda específica de projetos e pode liberar verbas através do Ministério da Presidência quando lhe pareça conveniente. A maioria dos projetos do TIPNIS são projetos Evo Cumple autorizados pelo então ministro Quintana à época da consulta. Muitos deles são parcialmente financiados por prefeituras dos municípios aos quais as comunidades do TIPNIS pertencem ${ }^{3}$.

Loreto (província Marbán, Beni) e Villa Tunari (província Chapare, Cochabamba). 
No território, ninguém esconde que o governo oferecia projetos e presentes em troca da realização da consulta. Embora essa dinâmica seja recriminada por uns e valorizada por outros, todos estão de acordo de que ela acontecia. A comunidade de Puerto San Lorenzo é uma das que mais recebeu projetos à época da consulta. Uma de suas autoridades afirmou em entrevista que "en esa consulta también se pidió otros beneficios para la comunidad, otros proyectos para la comunidad.(...) Se pidió ese motor que tenemos, ahí está el telecentro, ahí está la antena de celular - que hasta ahora no se ha cumplido”. Os projetos prometidos em 2012 vão sendo cumpridos aos poucos, até hoje, de modo que as comunidades seguem pendentes das boas relações com os dirigentes indígenas aliados ao governo já que eles intermediam a realização dos projetos com os órgãos públicos. Naquela mesma entrevista foi afirmado que "varios proyectos se pidió para que entre. Ahora estamos pidiendo que se cumpla, que no sea solamente que se quede ahí escrito sino que llegue a las comunidades, porque eso es un compromiso que ellos han hecho a través de la consulta" (24/09/16).

Os resultados da consulta agudizam mais ainda o quadro. Aqui me refiro tanto ao resultado oficial divulgado pelo governo, quanto à reação das comunidades em resistência e de ONGs que organizaram uma contra consulta. De acordo com o informe oficial do Estado, cinquenta e oito comunidades aceitaram receber a consulta e onze comunidades rejeitaram a entrada da consulta (o que totalizaria sessenta e nove comunidades no TIPNIS, cinco a mais do que o número de comunidades reconhecido pela Subcentral TIPNIS). Ainda de acordo com esse informe, das cinquenta e oito comunidades que receberam a consulta, cinquenta e sete teriam pedido a revogação da lei 180 de proteção ao TIPNIS e cinquenta e cinco teriam aceitado a construção da estrada Villa Tunari-San Ignacio de Mojos. Vale mencionar que nem as atas das reuniões comunais anexadas no livro oficial da $\mathrm{ABC}$ convencem sobre esse resultado favorável à estrada. Nos dois Encontros de Corregedores do TIPNIS que participei, em 2013 e 2016, escutei relatos sobre reuniões realizadas na base do engano e da chantagem. Além disso, o tema da estrada só aparecia em um terceiro momento da consulta, depois de perguntas sobre a intangibilidade e sobre as medidas protetivas adequadas para o TIPNIS. Essa terceira pergunta tampouco tratava diretamente sobre o polêmico projeto viário e abordava o tema das estradas de uma maneira ampla, questionando as comunidades sobre a necessidade de investimento em transporte que as favorecessem (BOLIVIA, 2012, p. 295). 
A Subcentral do TIPNIS, a Central de Pueblos Étnicos Mojeños del Beni e a Confederación de Pueblos Indígenas de Bolivia organizaram viagens pelas comunidades do território, e saíram de Trinidad rumo ao TIPNIS menos de um mês depois do início da consulta oficial do governo. Durante as semanas de viagens dos dirigentes pelos rios Isiboro, Sécure e Ichoa, foi estabelecido na comunidade de Gundonovia (a primeira comunidade do TIPNIS quando se sobe o rio Isiboro, sua porta de entrada) um grande acampamento da resistência à consulta. Comunarios e corregedores de várias comunidades foram apoiar a resistência, que também contava com a presença de ativistas e militantes de outras partes da Bolívia e de outros países. O rio foi fechado com arame farpado por alguns dias, para que houvesse controle das embarcações que entravam e saíam do TIPNIS. A brigada governista que tentava realizar sua consulta era monitorada pelos membros da resistência que tinham mais dois acampamentos estabelecidos no território (um na comunidade de Puerto Totora e outro na comunidade de Puerto San Lorenzo, ambas no rio Sécure).

O material divulgado pela Subcentral do TIPNIS como resultado desse trajeto, uma publicação financiada por ONGs bolivianas parceiras, sistematiza a posição de trinta comunidades do território, mas nem todas puderam ser visitadas e algumas relataram sua experiência com a consulta enquanto faziam parte da resistência em Gundonovia (SUBCENTRAL TIPNIS, 2012, p. 71-74). De acordo com esse material nenhuma das comunidades quereria a estrada, mesmo aquelas que haviam decidido receber a consulta oficial. Nessas visitas às comunidades os dirigentes debateram a estrada, a consulta do governo, a participação das comunidades no censo de 2012 e a continuidade da resistência no território. Não realizaram uma consulta alternativa, esse não era seu objetivo ou sua responsabilidade naquele momento. Tratava-se da organização da resistência que, naquele momento, já era resistência à estrada, à consulta e ao governo.

Houve, ainda, outro tour pelas comunidades do TIPNIS em 2012. Ele foi organizado pela Igreja Católica através da Pastoral Social Cáritas Boliviana e em coordenação com a Asamblea Permanente de Derechos Humanos de Bolivia. Foram percorridas trinta e cinco comunidades e mais o Centro de Gestão do TIPNIS para verificar os resultados divulgados pela consulta oficial. Os resultados apresentados no informe publicado pela pastoral (CÁRITAS, 2013) corroboram com a afirmativa de que a consulta do governo foi realizada em uma atmosfera de engano e 
chantagem. De acordo com os dados da Cáritas vinte e três das trinta e cinco comunidades visitadas por eles afirmaram que haviam tomado a decisão comunitária de não receber a brigada da consulta por imaginarem que sua presença significava a aceitação da estrada. Ainda assim, quinze comunidades declararam que mudaram de ideia porque a brigada da consulta oferecia presentes e prometia a construção de obras de colégios ou postos de saúde no local. Nove comunidades mencionaram que a consulta deveria ter sido realizada antes da assinatura do contrato com a OAS e do início das obras dos trechos um e três. Dezessete comunidades denunciaram que apenas algumas famílias receberam a brigada supostamente para pedir que se retirassem. Nove disseram que não foram notificadas sobre a chegada da consulta. Dezesseis disseram que as atas que o governo havia divulgado não eram documentos da comunidade porque não haviam sido produzidas no cabildo e sim entre alguns comunarios em casas particulares.

\section{Conclusão}

Na Bolívia, e em todos os lugares, não é suficiente realizar uma análise que generalize a situação dos direitos humanos, civis e políticos dos povos indígenas diante do Estado, seja ele ou não um Estado
Plurinacional. A pesquisa revelou que no TIPNIS a consulta se converteu em um problema político, na contramão do que poderiam supor análises menos dirigidas pela etnografia. Diferentes aspectos da consulta (normativos, contextuais e procedimentais) confluíram para que aquela experiência fosse percebida por lideranças e por comunarios enquanto uma afronta do governo do Estado Plurinacional à autonomia territorial. A polarização política entre governistas e opositores se transportou para o território ao longo da consulta, germinando em um ambiente de incertezas e necessidades para desabrochar enquanto divisão, desconfiança e aversão à política. A consulta, no TIPNIS, não é uma lembrada como uma conquista, mas como um momento em que "los políticos" impuseram suas vontades às comunidades.

A verdade é que existem muitas versões e muitas histórias desencontradas sobre a consulta ao TIPNIS, mas isso tem importância limitada diante da dimensão das consequências daquela experiência. Apesar de a consulta prévia se apresentar na Bolívia como um direito político dos povos indígenas diante da experiência de plurinacionalização e baseado no princípio da autodeterminação, como sugere Paz (2012, p. 18), no TIPNIS a consulta se transformou em outra coisa. A consulta foi uma trampa, uma armadilha política do 
governo. Ela reorganizou os discursos das lideranças indígenas daquela região a respeito de um direito globalmente reclamado como fundamental para a construção de sociedades mais jutas.

O direito à consulta prévia no TIPNIS foi convertido em um instrumento político manipulado pelo governo boliviano para facilitar seu acesso ao território em meio à crise que enfrentavam. A entrada do governo nas comunidades através do oferecimento de projetos e em nome da realização da consulta não passou despercebida enquanto uma manobra política, por isso há tanta polêmica sobre esse tema. Na comunidade de Coquinal, no rio Sécure, que conseguiu a liberação da construção de um colégio durante a consulta, me diziam que agora "ya no hay ganas de pedir cosas al gobierno, porque ya dicen que queremos carretera. Si él ayuda nosotros lo recibimos los proyectos, pero ya nos dicen que queremos carretera" (08/08/16). Depoimentos como esse são comuns nas comunidades que receberam os projetos do governo durante a consulta e revelam um descontentamento com a maneira como a política governamental criou uma associação entre a estrada e a chegada dos projetos no TIPNIS.

A ideia que se sobressai diante de toda essa situação é que é preciso trabalhar com o governo para que as necessidades básicas de uma comunidade sejam atendidas. Muitos disseram que hoje em dia, no TIPNIS, é preciso "tener color político" para conseguir algum projeto para sua comunidade. A alusão às cores políticas faz referência aos dois principais partidos que exercem influência no TIPNIS, os azuis (que são os governistas, militantes do MAS) e os verdes (que são a principal força da oposição de direita, do partido Democratas). A consulta tal como foi realizada partidarizou o que deveria ser um momento de reflexão das comunidades sobre o futuro do território em que convivem, criando novos dilemas no território sobre a política e demonstrando as contradições e ambivalências das relações internas ao campo político indígena quando perpassado por tensões próprias das políticas nacionais. A resistência à consulta adquiriu o caráter de oposição ao governo, consolidando um bloco de oposição indígena que se aproximou dos partidos de direita e segue atuante até hoje. A consulta serviu de munição para as disputas por hegemonia entre os atores que fazem parte do campo político indígena boliviano, e por isso que a etnografia dessas disputas permite que visualizemos melhor também o que significou aquela experiência e o próprio sentido da consulta como direito indígena. 


\section{Referências bibliográficas}

ALBÓ, Xavier. Una Mirada profunda al TIPNIS. In: CONTRERAS, A. Coraje, memorias de la Octava Marcha Indígena por la defensa del TIPNIS. La Paz: J.V. Editoras, 2012.

ALBUQUERQUE, Renata. Políticas Indígenas: análise a partir do Território Indígena e Parque Nacional Isiboro Sécure (TIPNIS). Tese de Doutorado. (DAN/UnB). Brasília, 2019.

BOLÍVIA, Informe final del proceso de Consulta Previa, Libre e Informada a los pueblos Moxeño-Trinitario, Yuracarpe y Chimane del Territorio Indígena y Parque Nacional Isiboro Sécure (TIPNIS), La Paz: 2012.

CHAVES, Cristhine de Alencar. A marcha nacional dos sem terra. Um estudo sobre a fabricação do social. Rio de Janeiro: Relume Dumará, 2000.

CHARRIS B., Juan Pablo. El consentimiento libre, previo e informado como garantía de transparencia en la administración pública. Revista Derecho del Estado n. 33, p. 123-147, 2014.

CIDOB; CONAMAQ; COICA; CAOI. Pueblos en el camino en defensa de los territorios. Bolivia, 2012.

CONTRERAS, Alex. Etapa de una larga marcha. La Paz: Asociación AQUÍ Avance, 1991.

. Coraje, memorias

de la Octava Marcha Indígena por la Defensa del TIPNIS. La Paz: J.V. Editoras, 2012.

GÚZMAN, Ismael. Octava Marcha

Indígena en Bolivia. Por la defensa del territorio, la vida y los derechos de los pueblos indígenas. La Paz: CIPCA, 2012.
LEHM, Zulema. Milenarismo y

Movimiento Sociales en la Amazonia

Boliviana: la búsqueda de la Loma Santa y la Marcha Indígena por el Território y la Dignidad. Santa Cruz de la Sierra: OXFAM, America, 1999.

PAZ, Sarela. El conflicto del Territorio Indígena y Parque Nacional Isiboro Sécure (TIPNIS) y sus consecuencias para el Estado Plurinacional de Bolivia. In: BAUTISTA, R.; CHÁVEZ, M.; CHÁVEZ, P.; PAZ, S.; PRADA, R. TAPIA, L. La Victoria Indígena del TIPNIS. La Paz, p. 11-68, 2012.

MORAES, Renata. Desenvolvimento e Vivir Bien. O caso do Território Indígena e Parque Nacional Isiboro Sécure (Bolívia). Dissertação de mestrado. (CEPPAC/UnB). Brasília, 2014.

SANTAMARÍA, Alejandro. La consulta previa desde la perspectiva de la negociación deliberativa. Revista Derecho del Estado, n. 36, p. 227-247, 2016.

SCHAVELZON, Salvador. Mutaciones de la identificacion indigena durante el debate del censo 2012 en Bolivia: mestizaje abandonado, indigeneidad estatal y proliferacion minoritaria. In. ANGOSTOFERNINDEZ, Luis e KRADOLFER, Sabine (Ed.) The Politics of Identity in Latin American Censuses. London and New York: Routledge, p. 8-34, 2016. 